DOI: $10.25100 /$ pfilosofica.v0i50.8665

\title{
VISIBILIDAD, CORPORALIDAD Y PUBLICIDAD EN LOS DISCURSOS GORGIANOS
}

\author{
Lucas Manuel Alvarez \\ Universidad de Buenos Aires, Buenos Aires, Argentina.
}

\begin{abstract}
Resumen
Nos proponemos en este trabajo resaltar un par de ejes significativos de la reflexión gorgiana soslayados por los intérpretes. Hablamos de los ejes de la visibilidad y de la corporalidad que, en el marco de un espacio público, parecen comportar para el sofista efectos quizás tan poderosos como los del lógos. Específicamente, indagaremos el rol que cumplen esas dimensiones en dos discursos gorgianos, Defensa de Palamedes y Encomio de Helena. En efecto, en sendas obras, la corporalidad y la visibilidad resultan, en mayor o menor medida, argumentos decisivos para demostrar la inocencia de Palamades y exculpar a Helena respectivamente.
\end{abstract}

Palabras clave: retórica; visibilidad; corporalidad; publicidad; vergüenza.

Cómo citar este artículo: Álvarez, L. M. (2020). Visibilidad, corporalidad y publicidad en los discursos gorgianos. Praxis Filosófica, (50), 41-64. doi: 10.25100/pfilosofica.v0i50.8665.

Recibido: 26 de marzo de 2019. Aprobado: 18 de agosto de 2019. 


\title{
Visibility, Corporality and Public Space in the Gorgias' Speeches
}

\author{
Lucas Manuel Álvarez ${ }^{1}$
}

\begin{abstract}
This paper highlights some significant topics in Gorgias' thought that have been overlooked by other interpreters: visibility and corporality. According to the sophist, these seem to have effects within the framework of a public space as powerful as those of discourse. Specifically, I research the role played by these dimensions in two of Gorgias' works, Defense of Palamedes and Encomium of Helen. In both these works, corporality and visibility are decisive arguments demonstrating Palamades' innocence and exonerating Helen, respectively.
\end{abstract}

Keywords: Rhetoric; Visibility; Corporality; Public; Shame.

${ }^{1}$ Profesor Universitario en Filosofía por la Universidad Nacional de General Sarmiento, Magíster en Estudios Clásicos y Doctor en Filosofía por la Universidad de Buenos Aires. En su tesis de maestría, defendida en julio 2014, abordó el enfoque performativo de la pólis ateniense brindado por los sofistas y en su tesis de doctorado, defendida en noviembre de 2018, se ocupó de la interpretación platónica de la sofística cifrada en el diálogo Sofista. Se desempeña como docente (ayudante de primera) en Historia de la Filosofía Antigua (FFyL, UBA). Ha publicado artículos en revistas especializadas en filosofía antigua de América Latina.

ORCID: 0000-0001-7571-6941 E-mail: lucasmalvarez@gmail.com 


\title{
VISIBILIDAD, CORPORALIDAD Y PUBLICIDAD EN LOS DISCURSOS GORGIANOS
}

\author{
Lucas Manuel Álvarez. \\ Universidad de Buenos Aires, Buenos Aires, Argentina.
}

En el marco de la discusión sobre la legitimidad de referirse a la sofística como un movimiento relativamente homogéneo de pensadores, un autor como Guthrie sostiene que es innegable que los sofistas compartían, al menos, un área de interés (Guthrie, 1969, p. 54). A juicio del autor, esos sofistas cultivaron, enseñaron y expusieron en manuales el arte del $\lambda o_{\gamma} \varsigma^{2}$, un arte que, podríamos añadir, no solo incluye la cuestión de las habilidades retóricas, sino que se extiende hacia ámbitos como la gramática o la crítica a la poesía ${ }^{3}$. Platón parece coincidir con ese juicio cuando presenta a Protágoras como un maestro en el arte de pronunciar agudos discursos (Protágoras 312d) cuya tarea supone modificar las disposiciones por medio de la palabra (Teeteto 167a) o cuando le hace decir a Gorgias que él debe ser llamado orador y reconocido como hábil en retórica (Gorgias 449a).

El interés sofístico por el $\lambda o ́ \gamma o \varsigma$ parece profundizarse en el caso de Gorgias si nos atenemos a las propuestas de los intérpretes modernos quienes suelen concentrarse tanto en sus tesis sobre los límites y los poderes de la palabra (expuestos en un tratado titulado Sobre el no-ser) como en sus

${ }^{2}$ Los sofistas solían ofrecer demostraciones o exposiciones públicas en espacios como el teatro, las escuelas, el gimnasio, las casas privadas o en ocasión de las competencias atléticas con el objeto de entretener, demostrar su maestría oratoria y atraer futuros estudiantes. Véase (DK82A1a y 9); (DK82B7, 8 y 9); (DK84B8 y 9); (DK86A9).

${ }^{3}$ Sobre esas áreas de interés, cf. Bonazzi (2010, pp. 96-99). 
propios discursos retóricos (posibles segmentos de manuales sobre retórica) ${ }^{4}$, uno de los cuales, Encomio de Helena, parece funcionar además como un encomio de ese mismo $\lambda$ ó ${ }^{5} \varsigma^{5}$. En sendos casos, la tesis del sofista supone la revelación de una nueva dimensión de la palabra que, lejos de restringirse a una función descriptiva o a una mera articulación de la experiencia, aparece como productora o como hacedora de mundo ${ }^{6}$.

Ahora bien, el objetivo de este trabajo es echar luz sobre ciertos pasajes de esos discursos retóricos, pasajes en general soslayados por los intérpretes, en donde el propio $\lambda$ ó $\gamma o \varsigma$ gorgiano se enfoca en los poderes que cobra específicamente lo corporal cuando se hace visible en los espacios públicos. Como han señalado varios especialistas, entre las características definitorias de la $\pi$ ó $1 \varsigma$ griega se encuentra la distinción entre un dominio público y otro privado, distinción a partir de la cual se coloca bajo la mirada de todos un conjunto de conductas que antes constituían un privilegio exclusivo del $\beta \alpha \sigma i \lambda \varepsilon v \varsigma^{7}$. En ese sentido, Hansen ha demostrado que las fuentes antiguas

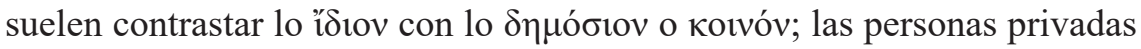

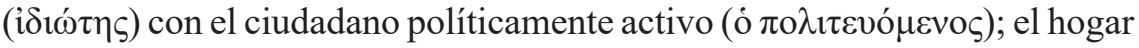
con los edificios públicos; los beneficios privados con los intereses de la

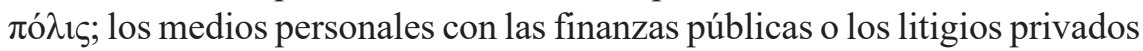
con las acciones legales de carácter público (Hansen, 1991, pp. 79-81; 2006, pp. 102-103, 122-124).

La absoluta visibilidad que caracteriza a esa arena pública ha llevado a intérpretes como Goldhill a pensar que las actividades e instituciones públicas clave de Atenas - como la Asamblea, la Corte, las competiciones atléticas, los rituales, las ceremonias religiosas o los festivales teatralespueden entenderse como un espectáculo. En efecto, todas esas instituciones dependen de una puesta en escena por medio de la cual su funcionamiento es observado, evaluado y, eventualmente, disfrutado por una audiencia (Goldhill, 1999 , pp. 2-9 $)^{8}$. Cabe aclarar que a la hora de intervenir en esas instituciones

${ }^{4}$ Debemos aceptar que, como bien señala Cany (2019, p. 15), Gorgias ha dejado de estar vinculado exclusivamente al campo retórico dada la revitalización de su postura metafísica. Sin embargo, aquí pretendemos poner en evidencia también sus reflexiones acerca del cuerpo, la visibilidad y lo público que también parecen ir más allá de aquella retórica.

${ }^{5}$ Entre la vasta bibliografía, cf., entre otros, Segal (1962), De Romilly (1973), Cassin (1995), Wardy (1996), Mazzara (1999), Consigny (2001) y McComiskey (2002). Si bien en muchos de estos casos se echa luz sobre posturas gnoseológicas o metafísicas de Gorgias estas suelen girar en torno a su concepción sobre el discurso.

${ }^{6}$ Cf. Cassin (1995, pp. 69-113).

${ }^{7}$ Cf. Vernant (1992, p. 63).

${ }^{8}$ Cf. además Segal (1995, pp. 213-221) para quien los atenienses eran un «pueblo de espectadores» acostumbrados a las grandes exhibiciones públicas como las competencias atléticas, las guerras, las ceremonias religiosas, los ritos mistéricos y, obviamente, el teatro. 
(e incluso en el propio ágora), los griegos ponían especial atención tanto a sus exposiciones verbales como a sus manifestaciones físico-corporales que podían acompañar sus discursos o cobrar fuerza independientemente de ellos. El mismo Goldhill señala que dos términos fundamentales para comprender ese funcionamiento de lo público son $\dot{\pi} \pi i ́ \delta \varepsilon 1 \xi ı$ (entendida no solo como una exposición verbal, sino también física) y $\sigma \chi \tilde{\eta} \mu \alpha$ que justamente apunta a la apariencia física que cada ciudadano expone ante la mirada evaluadora y reguladora de los otros, razón por la cual en el espacio que habilita esa exposición se juega la performance del sí-mismo (i.e. la auto-presentación, la auto-regulación y el auto-encubrimiento) (Goldhill, 1999, pp. 2-9). Por su parte, Frontisi-Ducroux encuentra que esa noción de $\sigma \chi \tilde{\eta} \mu \alpha$ designa toda una serie de actitudes corporales convencionales, y se encarga de señalar la importancia que, entre los griegos, adquiere el lenguaje de los rostros, el lenguaje de las miradas, lenguaje visual totalmente autónoma de las palabras (Frontisi-Ducroux, 1995, p. 55).

El cuerpo visible resulta, en definitiva, el centro neurálgico de las actividades públicas de los ciudadanos, y los sofistas no se mantuvieron al margen de ese fenómeno. Antifonte, por ejemplo, advierte que, al penetrar en la esfera pública, cada una de las partes del cuerpo (los ojos, los oídos, la lengua, las manos, los pies) debe adecuarse a los modos impuestos por la ley (DK87 B44A), mientras que Protágoras sostiene que, en el marco de la virtud política, si algún ciudadano sabe -por haber visto- que un par suyo se ha mostrado injusto (i.e. si ha aparecido ante los ojos de los otros violando algún acuerdo comunal) lo considerará loco, pues todos deben

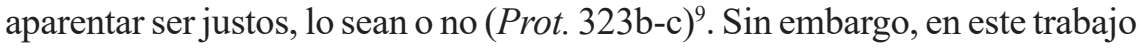
(y aunque hacia el final señalaremos algunas posibles conexiones entre los planteos gorgiano y protagórico), nos ocuparemos específicamente del sofista Gorgias. Indagaremos, en primer lugar, la centralidad que adquiere la visibilidad y lo público en Defensa de Palamedes, aunque sin perder de vista la incipiente dimensión corporal que allí aparece y, en segundo lugar, nos detendremos en Encomio de Helena, donde la visibilidad y la corporalidad operan como argumentos nodales de la defensa que busca exculpar a Helena.

\section{Visibilidad y publicidad en Defensa de Palamedes}

Podemos comenzar nuestro recorrido por Defensa de Palamedes, una apología judicial ficticia del personaje que le da título a la obra, un héroe mitológico - hijo de Nauplio y Clímene - conocido por su astucia

\footnotetext{
${ }^{9}$ Sobre el caso de Antifonte, cf. Álvarez (2011, pp. 9-29).
} 
e ingenio y, sobre todo, por sus numerosas invenciones ${ }^{10}$. Ausente en los poemas homéricos, su figura irrumpe en los Cantos Ciprios y en tragedias perdidas de Esquilo, Sófocles y Eurípides ${ }^{11}$, aunque las fuentes más copiosas sobre este héroe son Biblioteca mitológica de Apolodoro (2.1.5 y 3.2.2) y Fábulas de Higinio $(95,2)$. Según la versión dominante del mito, Palamedes habría desenmascarado el plan de Odiseo de hacerse pasar por loco para evitar el viaje a Troya. Razón por la cual, este último falsifica una carta de Príamo dirigida al propio Palamedes, en la que el héroe griego aparece dispuesto a traicionar a los suyos. Asimismo, para asegurar la consecución de sus propósitos, Odiseo habría escondido oro en la tienda de campaña de Palamedes como otra prueba del supuesto pacto concordado con el troyano. En consecuencia, el hijo de Nauplio habría sido condenado a muerte y ejecutado por un tribunal formado por aqueos ${ }^{12}$.

En el contexto de ese mito, Gorgias decide recrear el juicio en el que Palamedes se defiende ante dichos aqueos y, dada la ausencia de pruebas objetivas para demostrar su inocencia, pone en boca del acusado un notable discurso que se sostiene, según veremos, en argumentos que giran en torno a la cuestión de la visibilidad. De hecho, esa cuestión comienza a manifestarse ya en el proemio del discurso que reza así:

Tanto la acusación como la defensa no implican una decisión relativa a la muerte. Ya que la naturaleza, con voto manifiesto, ha condenado a muerte a todos los mortales en el mismo día en que nacieron. El peligro, más bien, radica en el honor o el deshonor: si debo morir de forma justa o de forma violenta cubierto de los ultrajes más graves y la acusación más vergonzosa. $(D P \S 1)^{13}$.

\footnotetext{
${ }^{10} \mathrm{~A}$ Palamedes se le adjudica la invención de los números, el uso de la moneda, el cálculo de los meses, el juego de las damas y de los dados y algunas letras del alfabeto. Sobre esta última creación, cf. Powell (1991, pp. 233-236). En cuanto a la fecha de composición del discurso gorgiano se cree que fue escrito entre el año 427 a.C. y el 380 a.C., aunque algunos autores acotan las fechas proponiendo el año 411 a.C. como término ante quem. Al respecto, cf. Clúa Serena (1985).

${ }^{11}$ En relación con la aparición de Palamedes en obras previas a la época clásica, cf. Szarmach (1974); sobre las tragedias perdidas, cf. Cropp (2005) y Giombini (2012, p. 149).

${ }^{12} \mathrm{Al}$ respecto, cf. Clúa Serena (2006, pp. 181-183). Véase, por otro lado, el Odiseo de Alcidamante, donde el personaje homónimo niega la enemistad con Palamedes (§4).

${ }^{13} \mathrm{El}$ discurso gorgiano se encuentra estructurado del siguiendo modo: introducción y presentación del tema $(D P \S \S 1-5)$; demostración de la inocencia $(D P \S \S 6-21)$; argumentación basada en la personalidad del acusador ( $D P \S \S 22-27)$; argumentación dirigida a los jueces (DP §§28-36) y epílogo (DP §37). Al respecto, cf. Untersteiner (1949, pp. 112-113). La traducción del texto le corresponde a Melero Bellido (1996) aquí y en citas ss. aunque modificada levemente siguiendo la edición de Diels y Kranz (1951-1952).
} 
En estas primeras líneas del discurso, el orador afirma que las instancias de un juicio no inciden sobre la muerte en sí - porque esa muerte está decidida de antemano por la $\varphi v ́ \sigma ı \varsigma-$, sino que determinan el tipo de muerte: una justa signada por el 'honor' ( $\tau \iota \mu$ ) o una muerte violenta signada por el

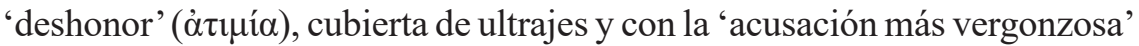

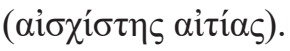

De manera implícita, Gorgias parece estar actualizando la clásica

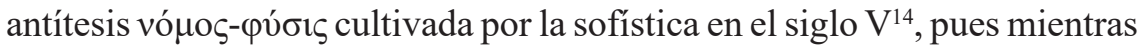
que, del lado de la pv́бıs, se impone una muerte a secas, en el espacio del

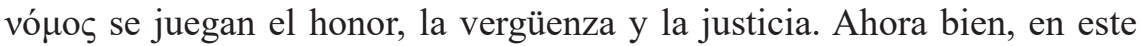
último espacio, teniendo en cuenta esas variables, lo que resulta decisivo es la dimensión visual. En principio, gracias a la incorporación de la $\tau \mu \eta ́$ que, desde tiempos homéricos, implica la honra, la estima y la valoración pública de un individuo, se asumen unas cuestiones que suponen reconocimiento social y, por ende, cierta visibilidad, cierta publicidad de aquel que goza del honor ${ }^{15}$. Asimismo, si tenemos en cuenta los significados del adjetivo

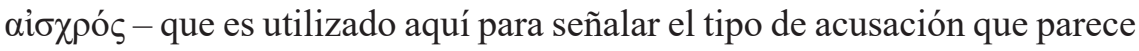
sufrir Palamedes- la dimensión visual cobra más densidad. En efecto, $\alpha i \sigma \chi \rho o ́ \varsigma$ puede referirse, sobre todo cuando se opone a $\kappa \alpha \lambda o ́ \varsigma$, , a la fealdad de una apariencia externa, aunque también puede significar, en un sentido moral, aquello digno de vergüenza o deshonra ${ }^{16}$. En el mismo campo

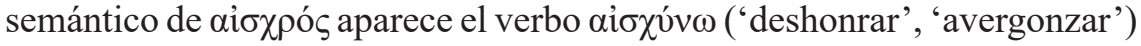

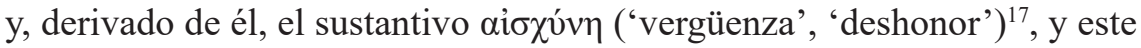
último término expresa, en su forma abstracta, la vergüenza que se siente por actos cometidos de manera real o aparente y, al mismo tiempo, la mala fama como sanción social que se obtiene o al contravenir códigos morales no escritos o al incumplir algún tipo de compromiso y/o norma ${ }^{18}$.

En relación con el significado de esos términos, Cairns sugiere que nuestro moderno concepto de vergüenza podría iluminar el sentido de

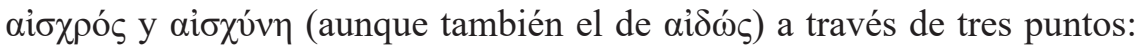
la presencia de un otro (de una especie de audiencia real o imaginaria), el intento de evadir la mirada de ese otro y, junto a ello, la cuestión de la

${ }^{14} \mathrm{Al}$ parecer una de las discusiones que aunaron a los sofistas es aquella que gira en torno a la cuestión de si las leyes, las instituciones y las costumbres sociales son por naturaleza o por convención. La obra más significativa dedicada al respecto es la de Heinimann (1945).

${ }^{15}$ Cairns (1993, p. 13 n. 27) advierte que Grecia antigua los valores del honor estaban estrechamente conectados con normas de adecuación que clasifican acciones o estados como bello, feo o impropio.

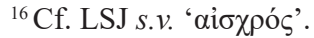

${ }^{17}$ Cf. Chantraine s.v. ' $\alpha i \sigma \chi u ́ v \omega '$.

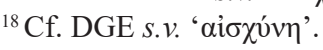


visibilidad o invisibilidad (Cairns, 1993, pp. 14-146) ${ }^{19}$. En este sentido, el propio Cairns define la vergüenza como una emoción inhibitoria de la acción que, teniendo en cuenta las normas ideales de la sociedad, protege la propia imagen ante la mirada de esos otros. A propósito de esta conexión estrecha entre vergüenza y visión, cabe citar a Aristóteles para quien " $<$ se siente vergüenza $>$ de lo que está a la vista y es más ostensible (de donde

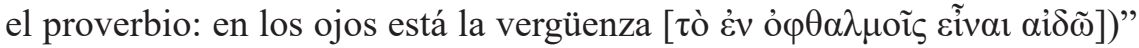
(Ret. 1384a 33-4). Como sugiere Grimaldi, el proverbio del que se hace eco el estagirita parece indicar que la vergüenza reside en aquellos actos de un sujeto que se hacen públicos, en aquellos actos que son vistos por los otros, razón por la cual, líneas después, el mismo Aristóteles sostiene que uno siente vergüenza ante quienes conviven con uno o se encuentran pendientes de uno,

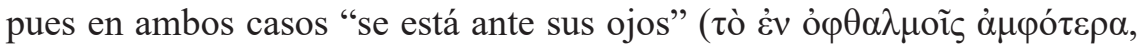
Ret. 1384b 1) (Grimaldi, 1988, p. 117).

Entre los sofistas, no solo Gorgias hace uso de esa noción, sino que Antifonte (DK87 B44A), el opúsculo Dissoì Lógoi (DK90 2) y también Protágoras apelan a ella para explicar el funcionamiento de la ciudad.

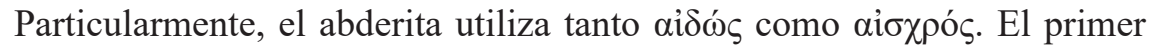
término aparece como una condición sine qua non para el establecimiento de cualquier ciudad (en la medida en que los hombres necesitan contar con esta virtud para estar atentos a las miradas de los otros, cuidar su imagen y no frustrar las expectativas de esos otros), y el segundo término para hablar de una ciudad en concreto como Atenas, en donde los padres, la nodriza y los pedagogos preparan a los niños para su vida ciudadana inculcándoles

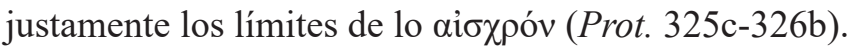

Retomando el discurso gorgiano, ahora resulta evidente que el uso del

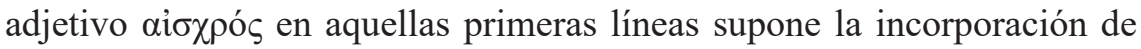
toda una dimensión visual que viene a señalar que el peligro mayor que se cierne sobre los afectados en un juicio no radica en la muerte a secas, sino en la posibilidad de morir cubierto de vergüenza, i.e. morir deshonrado

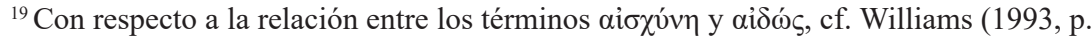
194 n.9) quien no diferencia los sentidos y usos de estos términos admitiendo que, en muchos

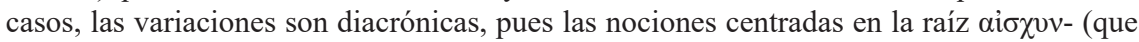
comporta el sentido de "estar avergonzado") tienden a reemplazar a aquellas centradas en la raíz $\alpha i \delta$ - (que comporta el sentido de "respetar el poder de..."). El autor cita el trabajo de Shipp, para quien ese reemplazo se da en la prosa ática, pero Konstan (2006, pp. 93-94) cuestionando esa hipótesis - afirma que, incluso en época clásica, y especialmente en poesía, el término aỉó́s sigue admitiendo ambos sentidos. El mismo Konstan advierte que los términos no son enteramente sinónimos, aunque al consultar los diccionarios lexicológicos encuentra cierta superposición de sentidos ya que ambas nociones pueden significar una virtud restrictiva.
} 
frente a la mirada de los conciudadanos. El peligro radica en que se hagan ostensibles las desgracias, los ultrajes, y, por ello, el orador afirma que su tarea es la de proteger la propia imagen ante los otros imponiendo justicia $(D P \S 2)$. Sin embargo, la dimensión visual - y junto a ella la cuestión de la mirada de los otros - se vuelven aún más explícitas líneas después, cuando el sofista configura una especie de espacio público.

Finalizando el proemio de su discurso, el orador afirma que mostrará su verdad de dos modos, ya que "ni si hubiese querido, habría podido, ni si hubiese podido, habría querido" ( $D P$ §5) emprender las acciones que se le imputan. Cabe indicar que, en las líneas siguientes, Gorgias apela al método apagógico o reductio ad absurdum, razón por la cual comienza suponiendo la negación de la tesis a demostrar y, por medio de una concatenación de inferencias lógicas, concluye en un absurdo, lo que vendría a demostrar que la hipótesis de partida es falsa y su contraria verdadera. Entonces, en relación con la primera alternativa (y ya en la sección dedicada especialmente a la demostración de su inocencia), Palamedes parte de la posibilidad de cometer la traición que se le endilga. No obstante, inmediatamente, sostiene que no tuvo el poder de cometerla ya que no hubo encuentro, conversación, juramentos ni intercambio de dinero entre él y un bárbaro $(D P \S \S 6-10)$.

En segundo lugar, suponiendo que ese encuentro se hubiera efectuado, señala que debería haberse ejecutado un plan, lo que implica problemas más insolubles que los anteriores: muchos habrían estado involucrados (libres que podrían oficiar de testigos o esclavos que podrían confesar bajo tortura) y hubiese sido necesario contar con enemigos en el propio territorio (DP $\S \S 11-12)$. Sin embargo, introducir enemigos resulta imposible, aclara el orador, porque el control sobre las entradas y salidas es tarea de los vigilantes y aun así, si hubiera podido evitarlos, su aparición "habría sido manifiesta

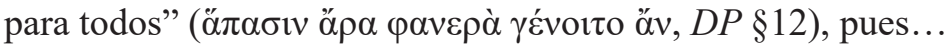

[...] al aire libre (vi $\alpha \dot{\theta} \theta \rho ı \varsigma)$ - ya que es un campamento - se hace la vida bajo las armas, en la que todos ven todo y todos son vistos por todos ( $\dot{\varepsilon} v$ oís

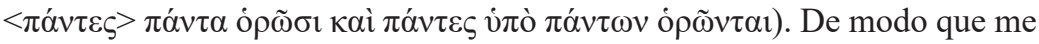

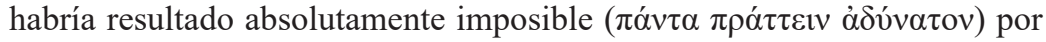
todos los conceptos llevar a cabo toda la empresa (DP §§12-3).

A nuestro entender, los argumentos de la primera alternativa ("si hubiese querido, no habría podido") concluyen con la configuración de una especie de ámbito público que es introducido por medio del término vi $\alpha \dot{\theta} \theta \rho ı \varsigma_{-}$ que comporta los sentidos de 'bajo el cielo', 'al aire libre' y, por extensión, 
'en público"20 - y se encuentra signado por dos principios que podríamos llamar el de "visibilidad integral" y el de "reciprocidad visual"21. Gracias al primer principio, todos tienen la posibilidad de ver todo y gracias al segundo principio, todos son vistos por todos. Entonces, es esa absoluta visibilidad de los hombres y de sus acciones la que coarta, en el discurso gorgiano, la posibilidad de ejecutar acciones pérfidas. Y este razonamiento no hace más que retomar los sentidos de una emoción como la vergüenza,

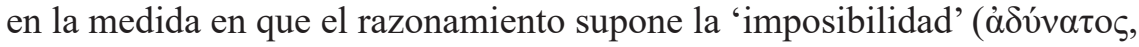
$D P \S 13)$ de una determinada acción que contraría las normas ideales de la sociedad (en este caso la fidelidad a la propia Grecia) debido a la eventual mirada del otro. El sofista parece sugerir que, una vez franqueados los límites del espacio privado y ante la mirada pública, un individuo procura no traicionar las expectativas de los otros mostrándose tal como los otros esperan que se muestre.

Antes de pasar a la segunda alternativa quisiéramos advertir que si bien Palamedes no apela específicamente al término $\sigma \tilde{\omega} \mu \alpha$ para referirse a esas irrupciones en el espacio público, resulta claro que al hablar de las puertas que deberían haber atravesado, de los muros que deberían haber traspasado, de las brechas que deberían haber abierto $(D P \S 12)$, el orador está pensando en lo insoslayable que hubiera sido su presencia física o la de sus cómplices "al aire libre". En el mismo sentido, y líneas antes, Palamedes deja en claro que de noche, debido a los numerosos puestos de 'vigilancia' ( $\varphi \nu \lambda \alpha \kappa \eta$, $D P$

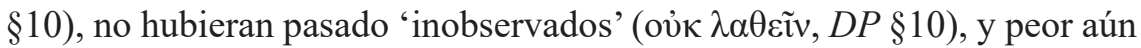
de día, pues la luz es enemiga de tales acciones $(D P \S 10)$. De nuevo aquí, el orador no utiliza el término $\sigma \tilde{\omega} \mu \alpha$, pero deja entrever que el cuerpo, ante la mirada de los vigiladores o a plena luz del día, es delator. El cuerpo no escapa a los ojos de los vigiladores y menos aún bajo la claridad del día. Por último, cabe señalar que, hacia el final de su discurso, Palamedes habla explícitamente de su cuerpo y lo hace en conjunto con la misma noción de $\varphi v \lambda \alpha \kappa \eta ́$ con el objeto de solicitar a los jueces que cuiden, que vigilen, su $\sigma \tilde{\omega} \mu \alpha(D P \S 35)$ mientras reflexionan y toman su decisión conforme a la verdad. El cuerpo vuelve aquí a ser un eventual delator, esta vez de las posibles injusticias cometidas por jueces que actúan de forma prematura.

Pasemos ahora a la segunda alternativa ("si hubiese podido, no habría querido"), en cuyo marco, Palamedes sostiene que, por ninguna razón, habría cometido la traición que se le endilga $(D P \S \S 15-19)$, pues traicionar a Grecia implicaría la imposibilidad de continuar su vida $(D P \S \S 19-20)$. En

\footnotetext{
${ }^{20}$ Cf. LSJ s.v. 'vं $\pi \alpha i \theta \rho ı \varsigma$ '.

${ }^{21}$ Sobre el principio de reciprocidad visual, propio del espíritu griego, cf. Frontisi-Ducroux (1995, pp. 46-53).
} 
este sentido, introduce el problema del sitio al que debería dirigirse luego de una eventual traición, aclarando que, por un lado, en el propio terreno griego habría recibido el castigo continuo de sus víctimas y que, por el otro, entre los bárbaros habría vivido "en medio de la vergonzosa infamia" ( $\dot{v} v \alpha i \sigma \chi i ́ \sigma \tau \eta 1$

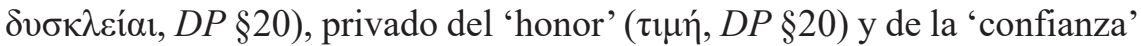
( $\pi i ́ \tau \tau 1 \zeta, D P \S 21$ ), sin la cual la vida no puede vivirse. Evidentemente, la

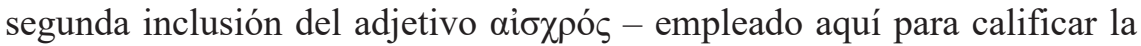

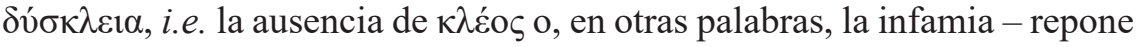
la cuestión de la visibilidad y de la mirada de los otros. El orador manifiesta que habitar entre los bárbaros habría significado permanecer entre aquellos que tienen la certidumbre de que uno ha cometido la acción más desleal, la de entregar sus amigos a sus enemigos $(D P \S 21)$, razón por la cual viviría bajo la presión constante de la mirada y de la opinión de los otros, quienes no dejarían de esperar la perpetración de una nueva felonía ${ }^{22}$. A ese escenario imaginado por Palamedes, podría aplicársele perfectamente la descripción, ofrecida por Williams y por Heller, del mecanismo propio de la vergüenza que opera en la víctima de tal emoción (Heller, 1985, p. 5 y Williams, 1993, p. 89). Hablamos del deseo de esconderse o incluso de desaparecer que afecta a esa víctima frente a observadores reales o imaginarios que, en este caso, no son otros que los bárbaros. Viviendo entre ellos, sin honor, sin confianza y en medio de la infamia más vergonzosa, Palamedes solo hubiese deseado tornarse invisible a los ojos de los otros, dejar esa "vida

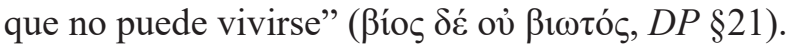

Concluida la sección dedicada a demostrar su inocencia por medio del método apagógico, el orador pasa a ocuparse, de manera inmediata, del estatus del acusador. Propone, ante todo, dejar en claro qué clase de hombre es Odiseo y cuál es la naturaleza de sus acusaciones y, por ello, establece una

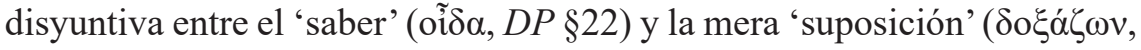
$D P \S 22)$. Esta segunda opción es descartada porque si Odiseo solo supone la ocurrencia de los hechos que le adjudica, eso no debería ser causa de una acusación de pena capital, pues las suposiciones no merecen confianza alguna ( $D P \S 24)$. Nos resta la primera opción, y en relación con ella cabe destacar que el verbo utilizado para referirse a ese eventual conocimiento de Odiseo es oĩ $\delta \alpha$ - un perfecto con valor resultativo, cuya forma reconstruida del presente es $\varepsilon i \delta \omega-$, término que implica saber, pero un saber por 'haber visto $^{23}$. Por ejemplo, en el corpus homérico, el uso de oĩ $\delta \alpha$ implica la idea de que la visión proporciona un conocimiento fidedigno de lo real, pues por

\footnotetext{
${ }^{22}$ Sobre el valor de la opinión de los otros en la construcción de inocencia de Palamedes, cf. Biesecker-Mast (1994, p. 153).

${ }^{23}$ Cf. LSJ s.v. 'oĩ $\delta \alpha$ '.
} 
medio de ella el hombre capta la "pluralidad de las cosas"24. En nuestro caso, Palamedes parece insistir con la preeminencia de lo visible y público a través de oĩ $\alpha$, al señalar que si Odiseo lo acusa porque tiene conocimiento de los hechos, entonces sabe o porque los ha visto o porque estuvo involucrado o porque los ha oído de otros. Entonces, añade, si se da el primer caso, debe decir cómo, cuándo y dónde sucedieron los hechos; si se da el segundo, resulta que él mismo es sospechoso y, en el último caso, el acusador debe presentar testigos $(D P \S \S 22-23)^{25}$. La publicidad y la visibilidad resultan determinantes, en la medida en que si Odiseo fue testigo de los hechos de los que habla, bien puede acusar a Palamedes (dando, claro está, los detalles de lo que ha visto). No obstante, el orador ya ha aclarado desde el comienzo que él "sabe con toda certeza" $(D P \S 5)$ que Odiseo no tuvo "constancia clara de los hechos" $(D P \S 5)$ porque no ha visto nada ${ }^{26}$.

A continuación, apelando al principio de no contradicción ${ }^{27}$, el orador le endilga a Odiseo el haberle atribuido dos cualidades (la sabiduría y la locura) que, siendo tan opuestas, no pueden ser poseídas por una misma persona, pues

[...] cuando afirmas que soy sagaz, hábil e ingenioso, me estás acusando de sabiduría; cuando, en cambio, dices que trataba de traicionar a Grecia, de locura. Porque la locura ( $\mu \alpha v i ́ \alpha)$ supone intentar acciones imposibles, inconvenientes, vergonzosas ( $\alpha i \sigma \chi \rho o i ́)$, de las que se seguirán daño para los amigos, beneficio para los enemigos y expondrán la vida de uno al oprobio

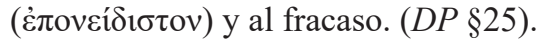

Si antes Palamedes ha configurado un espacio público en donde sus miembros procuran no traicionar las expectativas de los otros mostrándose

\footnotetext{
${ }^{24} \mathrm{Al}$ respecto, cf. Lesher (1981, pp. 2-24). En el Agamenón de Esquilo, el mismo verbo es utilizado para dar cuenta de la certeza que poseen los argivos respecto de los familiares que han despedido antes de su marcha a la guerra y, por contraposición, la incertidumbre que despiertan las cenizas que reciben a cambio, en la medida en que ellas no les permiten reconocer a los familiares (vv. 433-436). Cf. Douterelo Fernández (2004, pp. 16-20).

${ }^{25}$ Téngase en cuenta que tanto la acusación de Odiseo como el propio discurso de

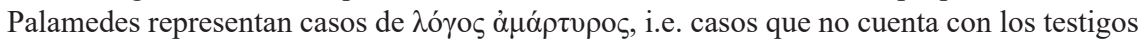
de los eventos en cuestión. Al respecto, cf. Giombini (2012, pp. 222-223).

${ }^{26}$ En ese pasaje, Gorgias apela en dos oportunidades al término oĩ $\delta \alpha$, en principio para decir que él 'sabe' (oî̃ $\delta$ ) con certeza, y luego para reiterar la idea sosteniendo que él "tiene clara conciencia ( $\sigma$ v́vi $\delta \alpha$ ) de no haber realizado ningún acto como aquel de que se me acusa" $(D P \S 5)$. Este último caso no es de nuestro interés dado que allí no parece ponerse en juego la idea de un saber por haber visto el cuerpo de otro, sino la de un saber que uno mismo no ha cometido determinada acción.

${ }^{27}$ Calogero (1957), Tordesillas (1990) y Giombini (2012) ven aquí una de las primeras formulaciones del principio de no contradicción, uno de los pilares de la lógica antigua.
} 
tal como estos esperan que se muestren, en las líneas que acabamos de citar refuerza esa lógica. ¿De qué modo? Considerando que la $\mu \alpha v i ́ \alpha$ como polo opuesto de la sabiduría, consiste en cometer, entre otras, acciones 'vergonzosas' ( $\alpha i \sigma \chi \rho o i ́)$, i.e. acciones que exponen al agente ante los ojos de los otros al quebrar sus expectativas. El cuerdo parece ser aquel que evita acciones públicas que contradigan los valores comunales, loco es aquel que emprende ese tipo de acciones. La presión ejercida por la visibilidad integral de las acciones que se practican en la arena pública convierte a aquel que transgrede las normas en un loco. Asimismo, Palamedes duplica la presencia del concepto de vergüenza (y su consabida vinculación con la mirada del

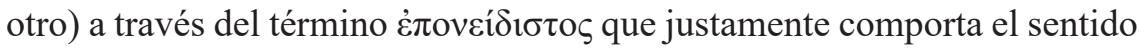
de ser avergonzado y viene a señalar las consecuencias del accionar propio de la locura ${ }^{28}$.

Por último, en la argumentación dirigida a los jueces, el orador comienza afirmando que se mantiene alejado de acciones 'vergonzosas' ( $\alpha i \sigma \chi \rho o i ́, D P$ §31) y, hacia el final, les advierte:

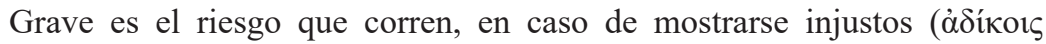

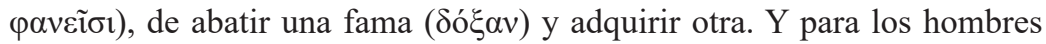

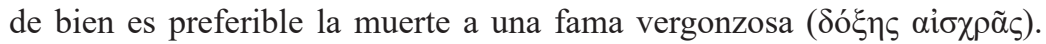
Aquella es el término de la vida, ésta una enfermedad para la vida. Si me condenas injustamente, ello resultará manifiesto para muchos. Puesto que yo [no] soy desconocido, su maldad será conocida y quedará en evidencia ( $\varphi \alpha v \varepsilon \rho \alpha ́$ ) ante todos los griegos. Y serán ustedes, y no mi acusador, los que soportarán, manifiesta ( $\varphi \alpha v \varepsilon \rho \alpha ́ v)$ para todos, la culpa de su injustica ( $D P$ $\S \S 35-36)$.

Con el objeto de amedrentar a los jueces, Palamedes advierte que si lo acusan injustamente, a él que es muy conocido, ellos aparecerán como injustos y obtendrán una fama vergonzosa que todo hombre de bien busca evitar más que a la propia muerte. Esta argumentación del tramo final del discurso también debe ser leída desde lo decisiva que resulta la dimensión visual.

En principio, el orador subraya la importancia de esa dimensión incorporando cuatro usos de un adjetivo como pavepós vinculado al

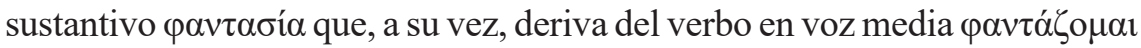
que significa 'volverse visible', 'aparecer', 'mostrarse'29. Palamedes advierte que i) la secuela de un juicio injusto "resulta manifiesta para muchos"

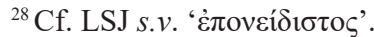

${ }^{29}$ Cf. LSJ s.v. ' $\varphi \alpha v \tau \alpha \sigma i ́ \alpha$ '.
} 


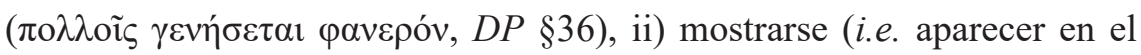
ámbito público ante los ojos de los otros) de forma injusta acarrea una fama vergonzosa, iii) la maldad ejercida contra un sujeto como él quedaría en "evidencia" ( $(\alpha v \varepsilon \rho \alpha ́, D P$ §36) y, por último, iv) que la culpa de un juicio injusto se torna "manifiesta" ( $\varphi \alpha v \varepsilon \rho \alpha ́ v, D P \S 36$ ) para todos. En los cuatro casos la advertencia dirigida a los jueces gira en torno al mismo eje, el de la peligrosidad que implica para los ciudadanos aparecer ante sus pares contraviniendo los valores convenidos. Al parecer, el principio de visibilidad integral que establecía los límites del accionar en la vida al aire libre de un campamento no solo reina en ese espacio particular, sino también en la ciudad toda. Y su importancia es tal que es utilizado por Palamedes como argumento final para convencer a los jueces: estos no deberían mostrarse de forma injusta porque no hay peor cosa que obtener una fama vergonzosa. En ese sentido, retomando planteos del comienzo del discurso, el orador supone que los hombres prefieren la muerte natural como fin de la existencia antes que dicha fama, pues esta, como una enfermedad, resulta una muerte en vida.

En suma, la publicidad y la visibilidad de las acciones operan como argumentos centrales en cuatro pasajes de Defensa de Palamedes: en primer lugar, comportando el peligro mayor que se cierne sobre los afectados en un juicio, peligro que se cifra en la vergüenza y el deshonor (una emoción y un desvalor que involucran la mirada y la opinión de los otros); en segundo lugar, como medios para justificar la imposibilidad del hecho adjudicado, en la medida en que se afirma que las acciones pérfidas no pudieron haberse realizado porque hubiesen sido visibles para todos; en tercer lugar, como justificativos de la inapetencia del hecho ya que el eventual traidor debería soportar una vergonzosa infamia que se traduce en una enfermedad para la vida y, en cuarto y último lugar, comportando el peligro mayor que se cierne ahora sobre los jueces que eventualmente tomen decisiones injustas que le acarrearán famas vergonzosas.

\section{Visibilidad y corporalidad en Encomio de Helena}

En Encomio de Helena ${ }^{30}$, Gorgias se ocupa de un tema de larga tradición literaria como lo es el de la culpabilidad o inocencia de la esposa de Menelao, quien, debido a su relación adúltera con Paris, huye a Troya desatando la guerra entre griegos y troyanos. Ahora bien, lo que parece buscar el sofista en este discurso no es tanto una reconstrucción de esos hechos, sino una reevaluación del juicio condenatorio que ha sufrido Helena ${ }^{31}$. En

\footnotetext{
${ }^{30}$ Sobre la probable fecha de composición del discurso, cf. Orsini (1956, pp. 82-88).

${ }^{31}$ En los poemas homéricos, Helena no aparece como un personaje del todo negativo: en Ilíada III 162-5, Príamo exculpa a Helena al responsabilizar de lo sucedido a los dioses y en
} 
ese sentido, ensayando una serie de estrategias argumentativas típicas de una defensa judicial ${ }^{32}$, presenta cuatro posibles causantes de su accionar. En un notable tour de force supone que Helena actuó como actuó forzada por alguna potencia sobrehumana como el azar los dioses o la necesidad, o raptada por la fuerza, o persuadida por el discurso ( $\lambda$ ó $\gamma$ o $\varsigma$ ), o presa del amor (ع $\mathrm{c} \omega \varsigma)$ ( $E H \S 6)$, y en todos estos casos Gorgias pretende demostrar que esas fuerzas mayores le quitan a Helena la responsabilidad de sus actos. Nuestra intención en este apartado, frente al grueso de lecturas que, como hemos afirmado, centran su atención sobre los poderes de la palabra expuestos por el sofista, es detenernos en el último posible causante del accionar de Helena donde, según pensamos, la dimensión visual y corporal cobra una fuerza equiparable a la del $\lambda$ ó $\gamma$ os.

No obstante, antes de ello, quisiéramos señalar que la cuestión del cuerpo y su visibilidad emerge ya en las primeras descripciones de Helena, pues el sofista sostiene que ella poseyó al nacer una belleza que no ocultó, y por esa razón "despertó en muchos numerosos deseos de amor y con un solo cuerpo congregó muchos cuerpos de hombres" $(E H \S 4)^{33}$. Gorgias comienza señalando que Helena hizo visible su belleza y en el marco de esa visibilidad establece un contraste entre un "único cuerpo" (غंvì $\sigma \omega ́ \mu \alpha \tau 1, E H$ $\S 4)$ y la "plétora" ( $\pi \lambda \varepsilon i ́ \sigma \tau \alpha \varsigma, E H \S 4)$ de cuerpos que ella atrae. La visible belleza del cuerpo de Helena funciona como una especie de imán que atrae a muchos otros cuerpos. Esta primera presentación de Helena podría estar evocando la $\varepsilon \varepsilon \iota \chi о \sigma \kappa о \pi i ́ \alpha$ de Iliada, donde la agitación que produce entre los muchos troyanos se debe al hecho de que ella - objeto ejemplar del deseo masculino - se muestra en público ${ }^{34}$. Pero la conexión más significativa para nosotros es aquella que parece darse entre esa primera descripción de Helena y la caracterización del $\lambda$ ó $\gamma o \zeta$. En efecto, en el contexto de la tercera posible causa, Gorgias afirma que el $\lambda$ ó $\gamma$ o $\varsigma$ "con un cuerpo pequeñísimo

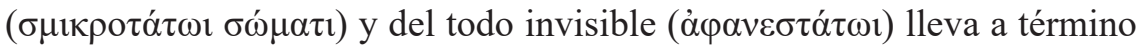

VI 344-358, Homero explica el amor y la pasión de Helena y Paris a través de la intervención de los dioses. Por el contrario, en Hesíodo, en Alceo y en la tragedia Troyanas de Eurípides, la esposa de Menelao es culpada por haber sido raptada de buena gana y no a la fuerza, pero también por su carnalidad y su conducta inmoral. Véase Hesíodo, Catálogo de las mujeres, V; Eurípides, Tr. 372-3 y Alceo fr. 1 del Pap. Oxy. \#2300. Sobre la incidencia del marginado rol de la mujer en la antigüedad griega sobre la valoración de Helena, cf. Bettini y Brillante (2008, p. 63).

\footnotetext{
${ }^{32} \mathrm{Al}$ respecto, cf. Buis (2016).

${ }^{33}$ La traducción aquí y en citas ss. le corresponde a Marcos y Davolio (2011).

${ }^{34}$ Cf. Worman (1997, p. 158).
} 


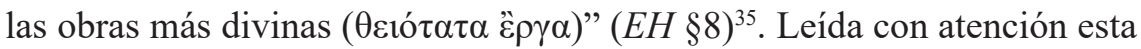
descripción plantea un contraste similar al que se había trazado a propósito del cuerpo de Helena: si el cuerpo único de Helena congregaba muchos cuerpos, aquí el cuerpo pequeño del $\lambda$ ó ${ }^{\prime}$ o lleva a cabo obras grandiosas. Sin embargo, el paralelo supone además una clara inversión: si Helena hizo

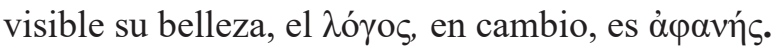

Detengámonos ahora en la exposición de la cuarta posible causa del accionar de Helena donde el sofista advierte que si ella fue víctima del amor, no le será difícil escapar de la acusación debido al consabido poder divino de ع̌ $\rho \omega \varsigma(E H \S 15)$. Ahora bien, a la hora de explicar ese poder, Gorgias no se enfoca en la dimensión religiosa, sino que a través de una lectura desacralizada estudia el medio de acción preferido de esa figura divina; a saber: la mirada que puede penetrar el alma ${ }^{36}$. Señala entonces que las cosas

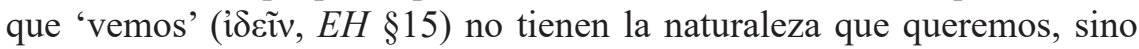
aquella que les es propia y que, a través de la 'vista' (ő $\psi 1 \varsigma, E H \S 15)$, el alma "recibe una impresión incluso en sus maneras", añadiendo luego que las 'imágenes' (Eíóvas, EH §17) de las cosas son grabadas en el entendimiento por la vista. Esta tesis gorgiana sobre la percepción - ejemplificada y desarrollada en los próximos parágrafos - parece suponer cierta emanación desde las cosas o acciones hacia la ő $\psi 1 \varsigma$ y de ahí al pensamiento o al alma donde son impresas y, por ello, ha sido vinculada con las propuestas acerca de los efluvios de Empédocles, de quien el sofista habría sido su pupilo ${ }^{37}$. Ahora bien, más allá del origen de su posicionamiento respecto de la visión, Gorgias precisa que aquellas impresiones que se producen en el alma se deben al poder subyugante de las imágenes que pueden o bien provocar terror, o bien producir deleite.

Ejemplifica el primer caso por medio de la visión que, al enfrentarse a 'cuerpos' ( $\sigma \omega ́ \mu \alpha \tau \alpha, E H ~ \S 16)$ de enemigos equipados con armaduras, se

${ }^{35}$ Téngase en cuenta que Gorgias no está pensando aquí en un homúnculo, sino que al hablar de la palabra como poseedora de un cuerpo parece querer decir que ella puede ser moldeada de diversas formas $\mathrm{y}$, al mismo tiempo, que tiene el poder de actuar sobre otros cuerpos. Asimismo, defendiendo esa tesis Gorgias estaría asumiendo perspectivas similares a las de ciertos filósofos como Demócrito y Anaxágoras, pero también a las de ciertos escritos médicos. Al respecto, cf. Ford (2002, pp. 175-179) y Holmes (2010, p. 212).

${ }^{36}$ Cf. Calame (1999, p. 5).

${ }^{37}$ En el diálogo Menón, Platón conecta a Gorgias con Empédocles al hablar de los poros de los seres hacia los cuales y a través de los cuales emanan efluvios, y específicamente del color como un efluvio de cosas proporcionado a la vista (Menón 76a y ss.). Al respecto, cf. Canto-Sperber (1991, pp. 234-235). Con respecto a la teoría de Empédocles, cf. Barnes (2000, pp. 562-569) y especialmente Wright (1991, pp. 230-231). Sobre las supuestas relaciones entre Gorgias y Empédocles, cf. DK82A2, A3 y A14 y Segal (1962, p. 101). 
turba $^{38}$. El mismo Gorgias especifica que ese pánico, que viene de la visión, puede hacerlos abandonar tanto lo correcto dictado por las normas como el bien que se deriva de la victoria $(E H \S 16)$.

Esa primera ejemplificación ofrecida por el leontinense reitera el contexto militar referido en Defensa de Palamedes, aunque mientras que allí nadie podía desear cometer acciones deshonrosas porque serían visibles para todos, aquí no se estudia tal constricción sobre el eventual agente, sino el efecto que la visibilidad tiene sobre los receptores. Sustituyendo al sujeto por la propia facultad sensitiva, Gorgias habla directamente de la 'visión' de cuerpos de soldados armados que 'turban' ( $\tau \alpha \rho \alpha ́ \sigma \sigma \omega, E H ~ \S 16)$ primero los ojos y luego el alma. Esa turbación del alma resulta tan violenta que las víctimas podrían dejar de lado las normas y la victoria, i.e. podrían desertar, una situación a la que justamente apuntan los sentidos arcaicos de un término que atravesó todo nuestro estudio de Defensa de Palamedes. Hablamos de $\alpha i \sigma \chi \rho o ́ \varsigma$ que, en época arcaica, refería al comportamiento cobarde de los soldados en la guerra ${ }^{39}$. De hecho, un sofista como Critias lo afirma de manera explícita al decir que "lo más vergonzoso ( $\alpha$ ǐ $\sigma \chi 1 \sigma \tau o v)$ de todo es arrojar el escudo en combate" (DK88B44) ${ }^{40}$. La contemplación de un cuerpo armado puede desviar a una persona de sus propósitos porque, en algunos, las visiones terroríficas pueden extinguir y expulsar "el entendimiento" ( ò vó $\mu \alpha, E H$ §17) e incluso provocar "terribles enfermedades y locuras incurables" ${ }^{\prime 1}$. Es evidente que el sofista presenta este panorama sombrío en el que el cuerpo y el alma de la víctima nada parecen poder hacer para resistir las fuerzas que los atormentan con el objeto de exculpar a Helena, pero aquí nos interesa remarcar que a la hora de elegir esas fuerzas inconmensurable

${ }^{38}$ Donadi (1978, pp. 44-77) ha conjeturado que esta escena compuesta de soldados abandonando el campo de batalla presos de pánico alude a la representación de una tragedia y, en particular, de Siete contra Tebas de Esquilo, aunque MacDowell (1982, p. 41) ha rechazado tal interpretación. Sobre la relación entre la representación del cuerpo y las armas y escudos, cf. Vernant (1989, p. 28).

${ }^{39}$ Cf. DGE s.v. ' $\alpha i \sigma \chi \rho o ́ \varsigma '$.

${ }^{40}$ Además, cf. Ilíada II 119 y 298.

${ }^{41}$ Segal (1962, p. 104) supone que la imagen de la enfermedad es sugerente en tanto implica una ecuación de la actividad psíquico-emotiva con procesos físiológicos tangibles. Sobre las posibles vinculaciones entre el tratamiento gorgiano de la visión y los escritos médicos contemporáneos, cf. Holmes (2010, pp. 213-214). Marcos (2011, pp. 67-68 n.35) entiende que la referencia a enfermedades y locuras apunta a la eliminación del discernimiento entre lo real y lo representado. MacDowell (1982, p. 41) advierte que según Gorgias el terror puede ser causado por visiones que presagian eventos en el futuro, por visiones de eventos presentes o por recuerdos de eventos vistos en el pasado. 
Gorgias no solo apela al discurso, sino también a las imágenes de cosas sensibles que afectan la visión ${ }^{42}$.

Volveremos luego a esa primera ejemplificación del poder subyugante de las imágenes, pero ahora es tiempo de leer la segunda ejemplificación iniciada del siguiente modo:

Por otro lado, los pintores, cuando a partir de muchos colores y cuerpos completan con perfección un solo cuerpo y figura deleitan a la vista. La creación de estatuas humanas y el tallado de esculturas proporcionan a los ojos un dulce espectáculo. $(E H \S 18)$

Probando que el poder de la imagen no está necesariamente unido al terror, sino que también puede darse bajo la forma del deleite, Gorgias retoma la variable corporal y la oposición entre muchos 'cuerpos', o 'elementos'

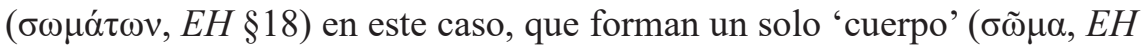
$\S 18)$ - el representado o por los pintores o por los escultores -, y añade que dicho cuerpo puede convertirse en un espectáculo para los ojos que despierta

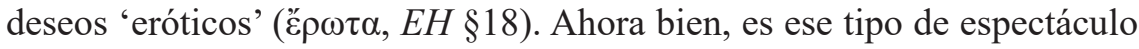
el que, según el sofista, forzó a Helena:

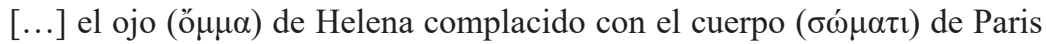

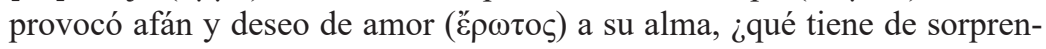
dente? Si amor es un dios, ¿cómo sería capaz de apartar y repeler la potencia divina de los dioses el que es inferior $(E H \S 19)^{43}$.

Ahora ya no es un cuerpo cualquiera retratado o esculpido el que deleita, sino el de Paris, ni tampoco es cualquier ojo el que se deleita, sino el de Helena. Sin embargo, la lógica es la misma: la visión de un determinado cuerpo provoca deseos de amor incontrolables en el ojo de otro. En las líneas citadas, Gorgias parece valerse de la difundida concepción sobre la potencia

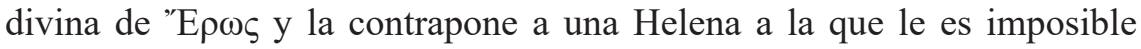
repelerla: incapaz de controlar su accionar, ella actuó como actuó presa de un amor irresistible ${ }^{44}$, pero como ya advertimos ese poder divino de "E $\omega \varsigma$

\footnotetext{
${ }^{42}$ Entre los pocos intérpretes que tienen en cuenta el papel de ambos objetos, cf. Casertano (1982, p. 24) y (1995, p. 17), Shaffer (1998) y Dinucci (2017).

${ }^{43}$ Cf. Chialva, Bonacossa, Casís y Omar (2013, p. 73) quienes hablan de 'mirada' en vez de 'ojo' al traducir ǒ $\mu \mu \alpha$.

${ }^{44}$ Sobre esa potencia divina, cf. Teogonía vv. 120-3, donde Hesíodo presenta a 'E $\omega \varsigma$ como el más hermoso entre los dioses inmortales y como aquel que "afloja los miembros y cautiva de todos los dioses y hombres el corazón y la sensata voluntad en sus pechos."
} 
solo es demostrado por medio de la potencia de la imagen y, en particular, de la imagen de los cuerpos sobre los ojos de los receptores ${ }^{45}$.

Del conjunto de razonamientos que estamos estudiando se desprende una primacía de la visión en el cuadro de los procesos cognoscitivos, en la medida en que la ǒ $\psi 1 \varsigma$ resulta la vía privilegiada a través de la cual los objetos se imprimen en el alma, el medio principal que determina la red de conexiones entre el hombre, los otros que lo rodean y el mundo ${ }^{46}$. Y en consonancia con lo expresado en la segunda tesis de su tratado Sobre el no ser, el leontinense estaría sugiriendo que lo que la ő $\psi 1 \varsigma$ capta no son más que los atributos visibles, aparenciales, (y nunca la realidad del objeto externo) ${ }^{47}$, por ejemplo, las de los cuerpos esculpidos en piedra que probablemente refieran a los aspectos ilusionistas del arte de la época o las de los cuerpos bellos que evocan el uso de la cosmética y la gimnasia ${ }^{48}$. Asimismo, en los casos señalados, esas apariencias ostentan un poder irrefrenable que las equipara con el $\lambda$ ó $\gamma$ s, razón por la cual la imagen también es un poderoso soberano que lleva a cabo obras divinas ( $E H$ §8). Tal como insiste Gorgias, los sujetos no son responsables de la naturaleza de lo que contemplan, cuya configuración les es propia, $\mathrm{y}$, entonces, dado que lo contemplado gatilla pasiones y estados motivacionales que los sujetos que no pueden controlar, estos no son responsables de lo que se desata en ellos ${ }^{49}$. Si Helena tiene ojos y estos ojos vieron a Paris, ella no puede ser culpable.

En suma, si en Encomio de Helena, el sofista busca exculpar a la esposa de Menelao presentando cuatro posibles causas de su accionar, causas que la convierten en paciente en vez de agente, lo cierto es que termina prestando especial atención a dos de ellas; a saber: al $\lambda o ́ \gamma o \varsigma$ (tal como insiste la mayoría de los intérpretes), pero también al amor y, específicamente, a las imágenes que atraviesan el ojo y el alma ${ }^{50}$. Incluso, siguiendo las sugerencias de

${ }^{45}$ Según sostiene Adkins (1983, p. 115), los razonamientos gorgianos sobre la dimensión visual se basan en una misma secuencia causal (objeto visible - imagen visual - emoción en el alma - acción) y para justificar el accionar de Helena, el sofista debe probar o bien que esa secuencia es siempre necesaria e inevitable o bien que toda vez que la acción resultante es reprochable, la secuencia es de tal naturaleza. Sin embargo, según el propio Adkins, Gorgias no parece demostrar ninguna de esas alternativas, sino que se limita a presentar casos extremos cuya existencia pocos se atreverían a negar.

${ }^{46} \mathrm{Al}$ respecto, cf. Casertano (1982, p. 24) y (1995, p. 17) y Giombini (2012, p. 140).

${ }^{47}$ Nos referimos a la segunda tesis que aparece en la versión MXG del tratado gorgiano según la cual ni la visión ni el pensamiento garantizan la existencia de un objeto externo a ellas ( $M X G$, 980a 9 y ss.). Al respecto, cf. Spangenberg (2011, pp. 58-67).

${ }^{48}$ Cf. Blondell (2013, p. 170).

${ }^{49}$ Cf. MacDowell (1982, p. 40) y Echeñique (2012, pp. 44-45).

${ }^{50}$ En el texto que nos ha llegado, se le dedican cantidades similares de parágrafos a la cuestión del discurso (siete) y a la cuestión del amor-imagen (cinco). 
Shaffer, podría pensarse que, al ubicar los argumentos sobre el amor y la dimensión visual en último lugar, el sofista parece entenderlos como los concluyentes y definitivos para quitarle las culpas a Helena (Shaffer, 1998, p. 256).

\section{Conclusiones}

Tanto en Defensa de Palamedes como en Encomio de Helena, Gorgias subraya con insistencia la importancia capital de la visibilidad (en particular la de ciertos cuerpos), de la percepción visual y de la reputación que las atraviesa. En el primer discurso, el héroe griego apela a los principios de visibilidad integral y reciprocidad visual para probar que no hubiese podido cometer la traición que se le endilga porque todos lo habrían visto y, en consecuencia, habría obtenido una fama vergonzosa que le hubiera impedido vivir. Por otro lado, en el discurso dedicado a Helena, nos encontramos con un caso complementario e inverso: la percepción de ciertas imágenes resulta tan determinante para el alma del receptor que este puede perder el control y actuar obviando las normas y los bienes. Ejemplos de ello son el soldado desertor y la Helena adúltera que actúan contra las normas (las de la guerra y las del matrimonio) y obtienen, por ello, una mala fama. No obstante, a pesar de que el desertor es el máximo infractor entre los hombres así como la Helena adúltera lo es entre las mujeres, tanto ese soldado como Helena pueden ser exculpados - sugiere Gorgias - porque ambos han sido conquistados por la tiranía de las imágenes frente a las cuales nada puede hacerse $^{51}$. En definitiva, en el marco de un espacio signado por la visibilidad, aparecer de determinado modo frente a los otros así como ser asaltados por las apariencias de los otros puede derivar en la obtención de una mala reputación, estigma entre los griegos.

Al comienzo de este trabajo afirmamos que era posible señalar una dirección hacia la que podrían apuntar los estudios que defienden la tesis de la sofística como un movimiento homogéneo, y ahora es tiempo de concluir indicando brevemente que esa dirección no es otra que la de las apariencias y su rol en la ciudad. En efecto, otro sofista como Protágoras -según el testimonio platónico-habría sostenido que, en el marco de la ỏpєtí política, i.e. en la arena pública, los ciudadanos "afirman que delira el que no aparenta ser justo, lo sea o no" (Protágoras 323b6). En dicho terreno no es suficiente ser mínimamente justo, sino que es necesario aparecer como justo, pues de no hacerlo el ciudadano será catalogado como un loco y perderá su lugar

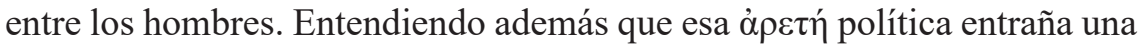

\footnotetext{
${ }^{51}$ Cf. Wardy (1996, p. 47).
} 


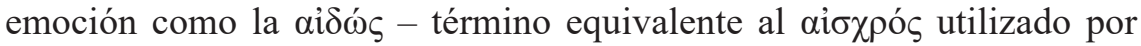
Gorgias -, la ciudad protagórica funciona en base a una red de miradas en la que el ciudadano-agente procura mostrarse justo sabiendo que así satisface las expectativas de sus pares, mientras que el ciudadano-espectador escudriña y controla las apariencias de los otros. Como puede apreciarse, tanto Gorgias como Protágoras a) leen la praxis de los sujetos como una determinada proyección de apariencias que constituye el eje de los espacios públicos signados por la visibilidad, b) entienden que, por medio de esas apariencias, es necesario proyectar lo instituido por la comunidad y ocultar aquello que lo contraría, c) iluminan la preeminencia de un sentimiento como la vergüenza y d) entienden que la locura y la muerte social (castigos que le advienen a los que se muestran injustos) representan las instancias que interrumpen las relaciones visuales recíprocas que definen la vida pública de los sujetos.

\section{Referencias bibliográficas}

Adkins, A. (1983). Form and Content in Gorgias' Helen and Palamedes: Rhetoric, Philosophy, Inconsistency and Invalid Argument in Some Greek Thinkers. En J. Anton y J. Preus (Eds.), Essays in Ancient Greek Philosophy (pp. 107- 28). Albany, EUA: State University of New York Press.

Álvarez, L. (2011). El uso de aischýne (vergüenza) en Antifonte y la política democrática de la Atenas clásica. Argos, 34(1), 9-29.

Bettini, M. y Brillante, C. (2008). El mito de Helena. Imágenes y relatos de Grecia a nuestros días. Madrid, España: Akal.

Barnes, J. (2000). Los presocráticos. Madrid, España: Cátedra.

Biesecker-Mast, G. (1994). Forensic Rhetoric and the Constitution of the Subject: Innocence, Truth, and Wisdom in Gorgias' Palamedes and Plato's Apology. Rhetoric Society Quarterly, 24(3-4), 148-166. doi: 10.1080/02773949409391024

Blondell, R. (2013). Helen of Troy: Beauty, Myth, Devastation. New York, EUA: OUP.

Boeri, M. (Trad.). (2006). Platón. Teeteto. Buenos Aires, Argentina: Losada.

Bonazzi, M. (2010). I sofisti. Roma, Italia: Carocci editori.

Buis, E. (2016). La defensa de las emociones: Gorgias y la producción retórica de páthe en el Encomio de Helena. Talia Dixit, (11), 1-18. doi: 10.17398/18869440.11.1.

Cairns, D. (1993). Aidōs. The psychology and ethics of honour and shame in Ancient Greek Literature. Oxford, Inglaterra: Clarendon Press.

Calame, C. (1999). The poetics of eros in Ancient Greece. Priceton, EUA: Princeton University Press.

Calogero, G. (1957). Gorgias and the Socratic Principle Nemo sua sponte peccat. The Journal of Hellenic Studies, 77(1), 12-17. doi: 10.2307/628627. 
Calonge Ruiz, J. (Trad.). (1992). Platón. Gorgias. Diálogos, Vol. II. Madrid, España: Gredos.

Calvo Martínez, J. (Trad.). (1985). Eurípides. Tragedias II. Madrid, España: Gredos.

Campbell, D. [Alceo] (1982). Greek Lyric I. Sappho and Alceus. Harvard, EUA: Harvard University Press.

Canto-Sperber, M. (Trad.). (1991). Platon. Ménon. Paris, Francia: GF Flammarion. Cany, B. (2019). Naissance de l'anthropologie philosophique : le moment sophistique. Praxis Filosófica, (49), 11-38. doi: 10.25100/pfilosofica.v0i49.7951

Casertano, G. (1982). «I dadi di Zeus sono sempre truccati». Considerazioni sulla parola, l'occhio e le passioni nell'Ellena di Gorgia. Discorsi, 2, 7-27.

Casertano, G. (1995). L'ambigua realtà del discorso nel Peri tou me Ontos di Gorgia (con un accenno all'Elena). Philosophica, (5), 3-18.

Cassin, B. (1995). L'effet sophistique. Paris, Francia: Éditions Gallimard.

Chantraine, P. (1968). Dictionnaire Étymologique de la langue grecque. Paris, Francia: Klincksieck.

Chialva, I. Bonacossa, M., Casís, M., y Omar, M. (Trads.) (2013). Gorgias. Encomio de Helena. Santa Fe, Argentina: Ediciones de la Universidad Nacional del Litoral.

Clúa Serena, J. (1985). El mite de Palamedes a la Grècia Antiga: aspectes canviants d'un interrogant cultural i històric. Faventia, 7(2), 69-93.

Clúa Serena, J. (2006). Palamedeia (iv): Acotaciones iconográfico-religiosas a la "justizmord" o muerte mítica de Palamedes. En E. Calderon Dorda, A. Morales Ortiz y M. Valverde Sanchez (Eds.), Koinòs Lógos. Homenaje al profesor José García López, Vol. I (pp. 181-186). Murcia, España: Universidad de Murcia Publicaciones.

Consigny, S. (2001). Gorgias. Sophist and Artist. Columbia, EUA: University of South Carolina Press.

Crespo, E. (Trad.). (2008). Homero. Ilíada. Barcelona, España: RBA Libros.

Cropp, M. (2005). Lost Tragedies: A survey. En J. Gregory (Ed.), A Companion to Greek Tragedy (pp. 271-292). Malden, EUA: Blackwell Publishing.

Cruces, J., Campos Daroca, J. y Marques Guerrero, M. (Eds. y Trads.). (2005). Alcidamante de Elea. Testimonios y fragmentos; Anaximenes de Lámpsaco. Retórica a Alejandro. Madrid, España: Gredos.

De Romilly, J. (1973). Gorgias et le pouvoir de la poésie. The Journal of Hellenic Studies, 93, 155-162. doi: 10.2307/631459.

Diels, H. y Kranz, W. [DK] (1951-1952). Die Fragmente der Vorsokratiker. Berlin, Alemania: Weidmann.

Dinucci, A. (2017). O Doce Encanto da Pintura e da Escultura no Elogio de Helena. En A. Dinucci (Ed.), Górgias de Leontinos (pp. 49-62). São Paulo, Brasil: Oficina do Livro.

Divenosa, M. (Trad.). (2006). Platón. Protágoras. Buenos Aires, Argentina: Losada.

Donadi, F. (1978). Gorgia, Elena 16 (Quel quattrocentocinque). Bollettino dell'Istituto di Filologia Greca, 4, 48-77.

Douterelo Fernández, E. (2004). El vocabulario del conocimiento en la obra de Esquilo (Tesis doctoral). Universidad Complutense de Madrid, Madrid, España. 
Echeñique, J. (2012). El Encomio de Helena y la responsabilidad moral. Méthexis, 25(1), 35-50. doi: 10.1163/24680974-90000595.

Ford, A. (2002). The Origins of Criticism Literary. Culture and Poetic Theory in Classical Greece. Princeton, EUA: Princeton University Press.

Frontisi-Ducroux, F. (1995). Du masque au visage. Aspects de l'identité en Grèce ancienne. Paris, Francia: Flammarion.

García Gual, C. (Trad.). [Prot.] (1982). Platón. Protágoras, Diálogos, Vol. I. Madrid, España: Gredos.

Giombini, S. (2012). Gorgia epidittico. Commento filosofico all'Encomio di Elena, all'Apologia di Palamede, all'Epitafio. Perugia, Italia: Aguaplano.

Goldhill, S. (1999). Programme notes. En S. Goldhill y R. Osborne (Eds.), Performance culture and Athenian Democracy (pp. 1-29). Cambridge, Inglaterra: Cambridge University Press.

Gorgias [DP] (1996) Defensa de Palamedes. En A. Melero Bellido (Trad.), Sofistas. Testimonios y Fragmentos (pp. 211-223). Madrid, España: Gredos.

Grimaldi, W. (1988). Aristotle. Rhetoric II. A Commentary. New York, EUA: Fordham University Press.

Guthrie, W. (1969). A history of Greek philosophy. Volume III: The fifth century enlightenment. Cambridge, Inglaterra: Cambridge University Press.

Hansen, M. (1991). The Athenian democracy in the age of Demosthenes: structure, principles, and ideology. Oxford, Inglaterra: Blackwell Publishers.

Hansen, M. (2006). Polis. An Introduction to the Ancient Greek City-State. Oxford, Inglaterra: Oxford University Press.

Heinimann, F. (1945). Nomos und Physis: Herkunft und Bedeutung einer Antithese im griechischen Denken des 5. Jahrhunderts. Basilea, Suiza: Wissenschaftliche Buchgesellschaft.

Heller, A. (1985). The Power of Shame: A Rational Perspective. Londres, Inglaterra: Routledge \& K. Paul.

Holmes, B. (2010). The Symptom and the Subject. The Emergence of the Physical Body in Ancient Greece. Princeton, EUA: Princeton University Press.

Jiménez, A. (Trad.). (2000). Hesíodo. Obras y Fragmentos. Barcelona, España: Editorial Gredos.

Konstan, D. (2006). The emotions of ancient Greeks. Studies in Aristotle and Greek Literature. Toronto, Canadá: University of Toronto Press.

Lesher, J. (1981). Perceiving and Knowing in the Iliad and Odyssey. Phronesis, 26(1), 2-24. doi: 10.1163/156852881X00105.

Liddell, H. y Scott, J. [LSJ (1996). Greek English Lexicon. (9ed.). Oxford, Inglaterra: Clarendon Press.

Marcos, G. (2011). Introducción. En G. Marcos y M. Davolio (Eds.), Gorgias. Encomio de Helena (pp. 11-21). Buenos Aires, Argentina: Ediciones Winograd. Marcos, G. y Davolio, M. (Eds.) [EH] (2011). Gorgias. Encomio de Helena. Buenos Aires, Argentina: Ediciones Winograd.

Mazzara, G. (1999). Gorgia. La Retorica del Verísimile. Sankt Augustin, Alemania: Academia Verlag. 
McComiskey, B. (2002). Gorgias and the New Sophistic Rhetoric. Carbondale, EUA: Southern Illinois University Press.

MacDowell, D. (Ed.). (1982). Gorgias. Encomium of Helen. Bristol, Inglaterra: Bristol Classical Press.

Melero Bellido, A. (1996). Sofistas. Testimonios y Fragmentos. Madrid, España: Gredos.

Orsini, M. (1956). La cronologia dell' 'Encomio di Elena' di Gorgia e le 'Troiane' di Euripide. Dioniso, 19, 82-88.

Powell, B. (1991). Homer and the origin of the Greek alphabet. Cambridge, Inglaterra: Cambridge University Press.

Racionero, Q. (Trad.). (1982). Aristóteles. Retórica. Madrid, España: Gredos.

Rodríguez Adrados, F. (Dir.) [DGE] (1980). Diccionario Griego-Español. Madrid, España: Consejo Superior de Investigaciones Científicas.

Segal, C. (1962). Gorgias and the Psychology of the Logos. Harvard Studies in Classical Philology, 66, 99-155. doi: 10.2307/310738.

Segal, C. (1995). El espectador y el oyente. En J.-P. Vernat (Ed.) El hombre griego (pp. 211-246). Madrid, España: Alianza Editorial.

Shaffer, D. (1998). The Shadow of Helen: The Status of the Visual Image in Gorgias's Encomium to Helen. Journal of the History of Rhetoric, 16(3), 243-257. doi: 10.1525/rh.1998.16.3.243.

Spangenberg, P. (2011). Gorgias. Sobre el no ser. Buenos Aires, Argentina: Ediciones Winograd.

Szarmach, M. (1974). Le mythe de Palaméde avant la tragèdie grecque. Eos, 62, 35-47.

Tordesillas, A. (1990). Palamède contre toutes raisons. En J.-F., Mattéi (Dir.), La naissance de la raison en Grèce. Actes du Congrès de Nice, mai 1987 (pp. 24155). Paris, Francia: Presses Universitaires de France.

Untersteiner, M. (1949). Sofisti, Testimonianze e Frammenti. Florencia, Italia: La Nuova Italia.

Vernant, J.-P. (1992). Los Orígenes del Pensamiento Griego. (M. Ayerra, Trad.). Barcelona, España: Paidós. (Trabajo original publicado en 1962).

Vernant, J.-P. (1989). Dim Body, Dazzling Body. En M. Feher, R. Naddaff y N. Tazi (Eds.), Fragments for a History of the Human Body, vol. 1 (pp. 18-47). New York, EUA: Zone Books.

Wardy, R. (1996). The birth of Rhetoric. Gorgias, Plato and their succesors. Londres, Inglaterra: Routledge.

Williams, B. (1993). Shame and Necessity. Berkeley, EUA: University of California Press.

Worman, N. (1997). The Body as Argument: Helen in Four Greek Texts. Classical Antiquity, 16(1), 151-203. doi: 10.2307/25011057.

Wright, M. (Trad.). (1991). Empedocles. The Extant Fragments. New Haven, EUA: Yale University Press. 